\title{
3-Hydroxypropionaldehyde production from crude glycerol by Lactobacillus diolivorans with enhanced glycerol uptake
}

\author{
Katharina Anna Lindlbauer ${ }^{1,2}$, Hans Marx $^{1,2^{*}}$ (D) and Michael Sauer ${ }^{1,2,3}$
}

\begin{abstract}
Background: In their quest for sustainable development and effective management of greenhouse gas emissions, our societies pursue a shift away from fossil-based resources towards renewable resources. With 95\% of our current transportation energy being petroleum based, the application of alternative, carbon-neutral products—among them biodiesel-is inevitable. In order to enhance the cost structure of biodiesel biorefineries, the valorization of the crude glycerol waste stream into high-value platform chemicals is of major importance.
\end{abstract}

Results: The purpose of this study is the production of 3-hydroxypropionaldehyde (3-HPA) from biodiesel-derived crude glycerol by Lactobacillus diolivorans. Particular focus is given on overcoming potential limitations of glycerol transport into the cell, in order to use the cells' total glycerol dehydratase capability towards the formation of 3-HPA as the main product. Recombinant overexpression of the endogenous glycerol uptake facilitating protein PduF results in a significant increase of glycerol conversion by a factor of 1.3. Concomitantly, glycerol dehydratase activity increased from initially $1.70 \pm 0.03 \mathrm{U} / \mathrm{mg}$ protein to $2.23 \pm 0.11 \mathrm{U} / \mathrm{mg}$ protein. With this approach, an average productivity of 4.8 $\mathrm{g}_{3-\mathrm{HPA}} /\left(\mathrm{g}_{\mathrm{CDM}} \mathrm{h}\right)$ yielding up to $35.9 \mathrm{~g} / \mathrm{L} 3-\mathrm{HPA}$ and $0.91 \mathrm{~mol}_{3-\mathrm{HPA}} / \mathrm{mol}_{\text {Glycerol }}$ have been obtained.

Conclusion: Lactobacillus diolivorans proves to be a valuable cell factory for the utilization of crude glycerol delivering high-value C3 chemicals like 3-HPA, 1,3-propanediol (1,3-PDO) and 3-hydroxypropionic acid (3-HP). Enhancing the glycerol influx into the cell by genetic engineering was successful paving the way towards the commercial production of 3-HPA.

Keywords: Lactic acid bacteria, Biodiesel, Biorefinery, Crude glycerol, Glycerol utilization, Glycerol uptake, Glycerol dehydratase

\section{Background}

Between 1970 and 2011, global greenhouse gas (GHG) emissions (particularly carbon dioxide) derived from fossil fuel combustion and industrial processes increased by $75 \%$ [1]. Key drivers for this dramatic increase in GHG can be related to alterations in population, structure of the economy, state of technology, and availability of fossil energy resources [2]. To counteract this trend, legal frameworks like the Paris Agreement aim at tackling global climate change, based on wide ranging changes

\footnotetext{
*Correspondence: hans.marx@boku.ac.at

${ }^{1}$ CD-Laboratory for Biotechnology of Glycerol, University of Natural Resources and Life Sciences, Vienna, Muthgasse 18, 1190 Vienna, Austria Full list of author information is available at the end of the article
}

and innovations for energy provision [3]. $60 \%$ of new power generation capacities are projected to be derived from renewables with the majority of them being competitive without any subsidies by 2040 [4]. This trend towards renewable energy technologies is also reflected in the growth of the global biofuels market-including biodiesel and bioethanol-from $\$ 148.5$ billion in 2015 up to $\$ 169.6$ billion until 2021 [5]. This performance is accompanied by an increasing availability of crude glycerol which is derived as a side stream from the transesterification process in amounts of $10 \%(\mathrm{w} / \mathrm{w})$ of the total biodiesel production volume [6, 7]. High abundance, low price, and high degree of reduction make glycerol an attractive feedstock for biorefineries [8]. However, crude 
glycerol contains many impurities, therefore cost-intensive product purification and recovery measurements are required for commercial sale in technical quality. The potential revenue is quite low due to the currently low spot price of $\$ 0.79 / \mathrm{kg}$ for technical quality refined glycerol [9-12]. Therefore, the upgrade of crude glycerol to high-value chemicals is desirable. A concomitant production of fuels and chemicals in an integrated biorefinery, meets the environmental and economic goals simultaneously, due to high-value chemicals becoming the economic driver for the entire production plant $[13,14]$.

A product of interest is 3-hydroxypropionaldehyde (3-HPA) which is currently available as a specialty chemical at a minimum price of $\$ 270 / \mathrm{g}$ (95\% purity, Atlantic Research Chemicals Ltd.) [15]. This metabolite is well known for its antimicrobial activity. A further market (albeit at significantly lower price) is addressed by its role as production intermediate for platform chemicals like 3-hydroxypropionic acid (3-HP), acrolein, or most importantly acrylic acid [16-18]. Chemical and biological approaches have been explored to convert glycerol into 3-HPA [6, 19]. The advantages of microbial conversion over conventional chemical production processes include higher specificity at moderate process conditions in regard to temperature and pressure, but also higher tolerance to impurities and the possibility to use variable feedstocks [20, 21]. Natural production of 3-HPA has been reported for species of Bacillus, Citrobacter, Clostridium, Enterobacter, Klebsiella, and Lactobacillus [18, 22, 23]. The microbial production is a simple one-step conversion process, catalyzed by the redox neutral action of glycerol dehydratase (GDHt) yielding 3-HPA by dehydration [24]. This conversion step is neither connected to the redox nor the energy metabolism of the cells. It is the first natural step of the metabolic pathways from glycerol to 1,3-PDO (electron sink) or to 3-HP (yielding one ATP and 2 electrons) [25]. Due to the high toxicity of 3-HPA, the metabolic pathways are tightly balanced in growing cells, to prevent any accumulation of the intermediate. Natural accumulation of 3-HPA has been reported to occur either due to an enzymatic imbalance, involving high glycerol dehydratase activity combined with low aldehyde dehydrogenase activity or in non-growing but metabolically active cells, also referred to as "resting cells." Such cells turned out to be quite favorable for the targeted production of 3 -HPA with minor accumulation of by-products $[26,27]$.

In this study, we are focusing on Lactobacillus diolivorans as microbial cell factory. The advantage of this organism is its ability to utilize both pharma grade, as well as crude glycerol without further processing steps, featuring no adverse impact of potential inhibitors on either growth or product yield. It has been shown that $L$. diolivorans is an excellent natural producer of 1,3-PDO and 3-HP, but the potential accumulation of 3-HPA has not been reported so far [28-30]. This study aims at a combinatorial approach of process and metabolic engineering to extend the product range of this cell factory towards the accumulation of 3-HPA. The main aspects include the evaluation of the glycerol uptake capabilities of $L$. diolivorans as well as the activity of glycerol dehydratase as both are key steps towards the formation of 3-HPA. The final aim is the establishment of an enhanced process for the production of 3-HPA from crude glycerol without application of any scavengers.

\section{Methods}

\section{Bacterial strains and plasmids}

Lactobacillus diolivorans LMG 19668 was used for all experiments in this study. The sequence of the glycerol facilitating protein PduF of $L$. diolivorans flanked by two BbsI restriction sites was ordered from IDT as part of a pUCIDT vector carrying a kanamycin resistance cassette. The expression of $p d u F$ was put under the control of the GAP promotor of $L$. diolivorans as well as the terminator of the chloramphenicol resistance cassette (TT_CAT) via GoldenMOCS [31], a modified form of Golden Gate cloning. This expression cassette was finally cloned into a vector carrying a replication origin of $L$. diolivorans (repA), as well as a kanamycin and erythromycin resistance (Additional file 1: Figure S1). In case of the empty vector (EV) control, the aforementioned vector was used without the introduction of an expression cassette for $p d u F$. The construction of plasmids was performed in E. coli $D H 1 O B$ and the final propagation for the delivery of non-methylated DNA took place in E. coli JM110. Detailed information regarding the used strains and design of the plasmids is available in Additional file 1: Table S1 and Table S2.

\section{Transformation procedure}

The transformation of plasmids was performed according to the protocol of Pflügl et al. [32] with some modifications which are described in brief. MRS medium " $\mathrm{pH}$ 5.7 " supplemented with $2 \%(\mathrm{w} / \mathrm{v})$ glucose was inoculated with a $1.5-\mathrm{mL}$ cryo stock of L. diolivorans LMG 19668 and incubated overnight $\left(30^{\circ} \mathrm{C}, 180 \mathrm{rpm}\right)$. An aliquot of this overnight culture was used to inoculate $500 \mathrm{~mL}$ MRS medium " $\mathrm{pH} 5.7$ " supplemented with $2 \%(\mathrm{w} / \mathrm{v})$ glucose and $1 \%(\mathrm{w} / \mathrm{v})$ glycine to an $\mathrm{OD}_{600}$ of $0.25 \mathrm{AU}$. After $3 \mathrm{~h}$ of incubation $\left(30{ }^{\circ} \mathrm{C}\right.$, without shaking), cells were harvested by centrifugation $\left(5 \mathrm{~min}, 4000 \mathrm{~g}, 4{ }^{\circ} \mathrm{C}\right.$ ), washed four times with $0.3 \mathrm{M}$ sucrose supplemented with $20 \mathrm{mM}$ $\mathrm{MgCl}_{2}$ and once with $0.3 \mathrm{M}$ sucrose. The cells were finally resuspended in an electroporation buffer $(272 \mathrm{mM}$ sucrose, $7 \mathrm{mM}$ sodium phosphate, $0.5 \mathrm{mM} \mathrm{MgCl}_{2}, \mathrm{pH}$ 7.4). An $80 \mu \mathrm{L}$ aliquot of cells was mixed with $20 \mu \mathrm{L}$ DNA 
solution $(3 \mu \mathrm{g})$ and electroporation was carried out at $2500 \mathrm{~V}, 200 \Omega$, and $25 \mu \mathrm{F}$ in an electroporation cuvette with 4-mm gap width. Immediately after, the cells were resuspended in $900 \mu \mathrm{L}$ MRS medium "pH 5.7" supplemented with $2 \%(\mathrm{w} / \mathrm{v})$ glucose, $0.3 \mathrm{M}$ sucrose, and $20 \mathrm{mM}$ $\mathrm{MgCl}_{2}$. This mix was transferred into a 1.5-mL Eppendorf tube, placed on a tube rack and positioned in a shaking incubator $\left(30{ }^{\circ} \mathrm{C}, 180 \mathrm{rpm}, 3 \mathrm{~h}\right)$. After this regeneration period, the cell suspension was plated on degassed MRS plate's "pH 5.7" containing $2 \%(\mathrm{w} / \mathrm{v})$ glucose and $2.5 \mu \mathrm{g} /$ $\mathrm{mL}$ erythromycin and was incubated in an anaerobic jar at $30^{\circ} \mathrm{C}$ for 3 days.

\section{Growth medium}

The cultivations were performed in a two-step cultivation process. First of all, biomass was generated in a seed reactor containing a modified form of the MRS medium as described by De Man et al. [33] supplemented with $5 \mathrm{mg} / \mathrm{L}$ vitamin $\mathrm{B}_{12}, 2.5 \mu \mathrm{g} / \mathrm{mL}$ erythromycin, 3\% (w/v) glucose and either $1 \%(\mathrm{w} / \mathrm{v})$ crude glycerol or $0.5 \%(\mathrm{w} / \mathrm{v})$ 1,2-PDO. The second step, namely biotransformation, was performed in varying amounts of crude glycerol supplemented with $5 \mathrm{mg} / \mathrm{L}$ vitamin $B_{12}$ and $2.5 \mu \mathrm{g} / \mathrm{mL}$ erythromycin. Crude glycerol used in this study was obtained from Universal Adsorbent \& Chemicals Public Co. Ltd. Thailand and had an original concentration of $810 \mathrm{~g} / \mathrm{L}$ glycerol. For the individual experiments, crude glycerol was used without further pretreatment and was accordingly diluted with water. The medium of the seed reactor was adjusted to $\mathrm{pH} 5.7$ using $32 \% \mathrm{HCl}$, whereas the medium for biotransformation was adjusted to $\mathrm{pH} 7$ using $4 \mathrm{M} \mathrm{NaOH}$. Both media were supplemented with $1 \%$ (v/v) Struktol ${ }^{\circledR}$ SB2121 dropwise to avoid foam formation, when required.

\section{Bioreactor cultivations}

All bioreactor cultivations were performed in DASGIP ${ }^{\circledR}$ parallel bioreactor systems (Eppendorf International) using three biological replicates-if not otherwise mentioned. For the seed reactors, an initial cultivation volume of $700 \mathrm{~mL}$ was inoculated to an $\mathrm{OD}_{600}$ of $0.2 \mathrm{AU}$ (initial active biomass characterization experiments) or $0.4 \mathrm{AU}$ (active biomass for biotransformation experiments) with $1.5 \%(\mathrm{v} / \mathrm{v})$ inoculum from an exponentially growing preculture. These seed reactors were operated at a constant

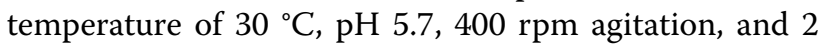
$\mathrm{sL} / \mathrm{min} \mathrm{N}_{2}$-gassing in order to maintain anaerobic conditions. Throughout the cultivation process, $\mathrm{pH} 5.7$ was maintained by the use of $12.5 \% \mathrm{NH}_{3}$ as base supply.

\section{Cell harvest}

Towards the end of the exponential growth phase, cells were harvested by centrifugation $\left(4000 g, 5 \mathrm{~min}, 20^{\circ} \mathrm{C}\right)$.
The pellet was washed with sterile water, centrifuged again and finally resuspended in sterile water accounting for $1.5 \%(\mathrm{v} / \mathrm{v})$ of the original seed culture volume.

\section{Biotransformation}

The cell fraction from the seed reactors was used as inoculum for the biotransformation process. Thereby the reactors were operated with a culture volume of $350 \mathrm{~mL}$ at a constant temperature of $30^{\circ} \mathrm{C}, \mathrm{pH} 7,400 \mathrm{rpm}$ agitation, and $2 \mathrm{sL} / \mathrm{min} \mathrm{N}_{2}$-gassing. Throughout the cultivation process, $\mathrm{pH} 7$ was maintained by the use of $12.5 \%$ $\mathrm{NH}_{3}$ as base supply.

\section{Measurement of cell growth}

Biomass production was determined by measuring the optical density at $600 \mathrm{~nm}$, and cell dry mass (CDM) was calculated by a correlation established by Pflügl et al. [28].

\section{Quantification of extracellular metabolites}

Extracellular metabolites like D-glucose, glycerol, 3-HPA, 3-HP, 1,2-PDO, 1,3-PDO, lactic acid, acetic acid, and ethanol were determined by HPLC analysis (Shimadzu, Korneuburg, Austria) with an Aminex HPX-87H column $(300 \mathrm{~mm} \times 7.8 \mathrm{~mm}$; Biorad) equipped with a MicroGuard Cation H Cartridge $(30 \mathrm{~mm} \times 4.6 \mathrm{~mm}$, Biorad). The column was operated at $60{ }^{\circ} \mathrm{C}$ and a flow rate of $0.6 \mathrm{~mL} / \mathrm{min}$ with $0.004 \mathrm{M} \mathrm{H}_{2} \mathrm{SO}_{4}$ as mobile phase. A refraction index detector (RID-10A, Shimadzu, Korneuburg, Austria) and a UV-VIS photodiode array detector (SPD-M20A, Shimadzu, Korneuburg, Austria) were used for detection. We observed a tailing peak for 3-HPA in the RID detector which is overlapping with the peak of 1,3-PDO and therefore compromising the accurate quantification of this metabolite. As a result thereof, 3-HPA quantification was performed by using the UV detector at $210 \mathrm{~nm}$ [34] where the presence of small amounts of 1,3-PDO can be neglected due to its extremely low signal intensity (Additional file 2: Figure S2). Moreover, as the concentration of 1,3-PDO cannot exceed the levels of equimolar amounts of 3-HP, maximum levels of $0.84 \mathrm{~g} / \mathrm{L}$ are expected in the presence of $1 \mathrm{~g} / \mathrm{L} 3-\mathrm{HP}$.

\section{Cell breakage}

Cells from the seed reactors or the biotransformation process were centrifuged $\left(15,000 \mathrm{~g}, 2 \mathrm{~min}, 4{ }^{\circ} \mathrm{C}\right)$, washed with degassed $20 \mathrm{mM}$ potassium phosphate buffer $(\mathrm{pH}$ 8 ) and resuspended in the same buffer. Cell suspensions were subjected to physical cell disintegration by a Bead Beater (Fast-Prep-24TM, MP biomedicals, USA) at $6 \mathrm{~m} / \mathrm{s}$ for $20 \mathrm{~s}$ (5 cycles). Broken cells were centrifuged $(15,000 \mathrm{~g}$, $20 \mathrm{~min}, 4{ }^{\circ} \mathrm{C}$ ) and the supernatant was collected in an anaerobic atmosphere to measure glycerol dehydratase activity [35] and protein concentration [36]. 


\section{Glycerol dehydratase activity assay}

GDHt activity from crude cell extract was measured according to the protocol of Sankaranarayanan et al. [35]. The composition of substrate mixture was $20 \mathrm{mM}$ potassium phosphate buffer ( $\mathrm{pH} 8), 3 \mathrm{mM} \mathrm{MgCl} 2$, and $40 \mathrm{mM}$ 1,2-PDO and coenzyme solution contained $15 \mu \mathrm{M}$ vitamin $\mathrm{B}_{12}, 0.15 \mathrm{mM} \mathrm{NADH}$, and $1.5 \mathrm{mM}$ ATP as well as $24 \mathrm{U} / \mathrm{mL}$ yADH as coupling enzyme.

\section{Results and discussion}

\section{Evaluation of major bottlenecks attributed to 3-HPA} formation in L. diolivorans

The most crucial steps for the production of 3-HPA are the initial uptake of glycerol into the cell, followed by the conversion of the intracellular glycerol into 3-HPA by glycerol dehydratase (see Fig. 1). Members of the genus Lactobacillus are reported to accumulate 3-HPA extracellularly, ensuring a low, non-toxic level of intracellular 3-HPA [18, 37]-pointing to the fact that export is not limiting. Taking furthermore into account that the exporting transporters are currently not known, the following study is focusing primarily on limitations related to the glycerol uptake and further conversion to 3-HPA.

A first set of experiments aimed at the comparison of the GDHt activity with the actual rate of glycerol to 3-HPA conversion. To this end, batch cultures on MRS medium supplemented with 3\% (w/v) glucose and $1 \%(\mathrm{w} / \mathrm{v})$ glycerol were performed. Under this condition, 3-HPA is entirely converted into 1,3-PDO [28]. This conversion step proceeds in a fast and efficient manner within growing cells, ensuring that the concentration of

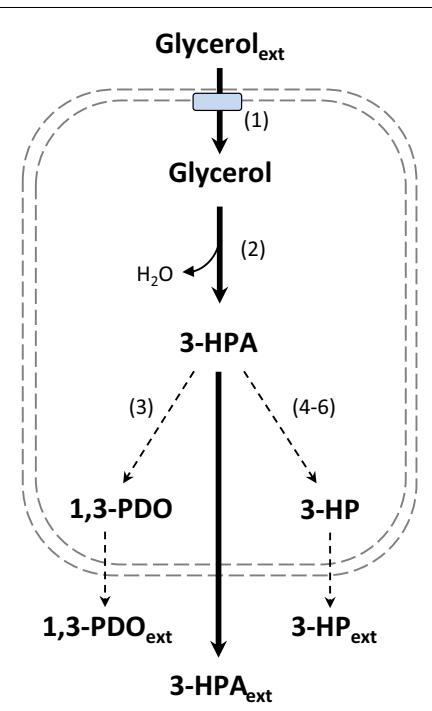

Fig. 1 Utilization of glycerol in L. diolivorans. Illustration of the pathway for glycerol utilization in L. diolivorans. (1) Glycerol facilitator protein PduF; (2) vitamin $\mathrm{B}_{12}$-dependent glycerol dehydratase PduCDE; (3) 1,3-PDO oxidoreductase PduP; (4) PduP; (5) PduL; (6) PduW toxic 3-HPA is kept low. We opted for this setup to gain insight into the potential of the biomass for the desired conversion without any interference of 3-HPA toxicity.

Lactobacillus diolivorans is not able to use glycerol as a sole carbon and energy source. This was confirmed by substrate utilization tests and $\mathrm{C}^{13}$ labeling experiments (data not shown). This characteristic is also reported for Lactobacillus reuteri, which lacks a dihydroxyacetone kinase required for channeling glycerol into the central carbon metabolism [24]. Genome analysis of $L$. diolivorans reveals that a bona-fide dihydroxyacetone kinase is also missing in this organism. There is a bioinformatic annotation for a "kinase to dihydroxyacetone kinase" (83 amino acids, NCBI Sequence ID: WP_057864359.1), which is rather short compared to the 356 amino acid long dihydroxyacetone kinase of other organisms like $K$. pneumoniae [38, 39] and therefore most probably not functional. This could be the reason why glycerol cannot serve as sole carbon and energy source in L. diolivorans.

Glycerol is converted via a one-step reaction towards the formation of 3-HPA in $L$. diolivorans. This reaction is catalyzed by a glycerol dehydratase, encoded by the gene cluster $p d u C D E$ [40]. As there is no side reaction diverting the flux of glycerol into biomass formation, the glycerol uptake rate is equal to the rate of glycerol conversion to 3-HPA. In addition to this, the potential of glycerol conversion based on the present GDHt activity can be derived via an in vitro enzymatic assay from crude cell extract as described by Sankaranarayanan et al. [35]. These two values are based on either cell dry mass-in case of glycerol uptake and conversion ratesor on measured protein content of the crude cell extract in case of enzymatically measured GDHt activity. Both values can be compared based on the assumption of bacterial protein content accounting for around $50 \%$ of CDM $[35,41,42]$.

$$
\begin{aligned}
& \text { Glycerol uptake rate } q_{\mathrm{s}}\left[\mathrm{g} / \mathrm{g}_{\mathrm{CDM}} \mathrm{h}\right] \\
& =\left(\frac{\text { Glycerol }_{\text {final }}-\mathrm{Glycerol}_{\text {initial }}}{\Delta \text { Time }}\right) / \mathrm{CDM}
\end{aligned}
$$

The performance of batch cultures of $L$. diolivorans LMG 19668 + EV is illustrated in Fig. 2a. Under this condition, glycerol is solely converted to $1,3-\mathrm{PDO}$ as final product, without accumulation of 3-HPA or 3-HP in the fermentation broth [28]. The detailed analysis of these batch cultivations indicated that there is a significant discrepancy between the rate of glycerol conversion which equals the glycerol uptake rate. The required GDHt activity for this conversion can be calculated-it equals approximately $0.07 \mathrm{U} / \mathrm{mg}$ protein. The in vitro measured GDHt activity at the end of the exponential growth phase is $0.13 \mathrm{U} / \mathrm{mg}$ protein (Fig. 3). These results show that $L$. 

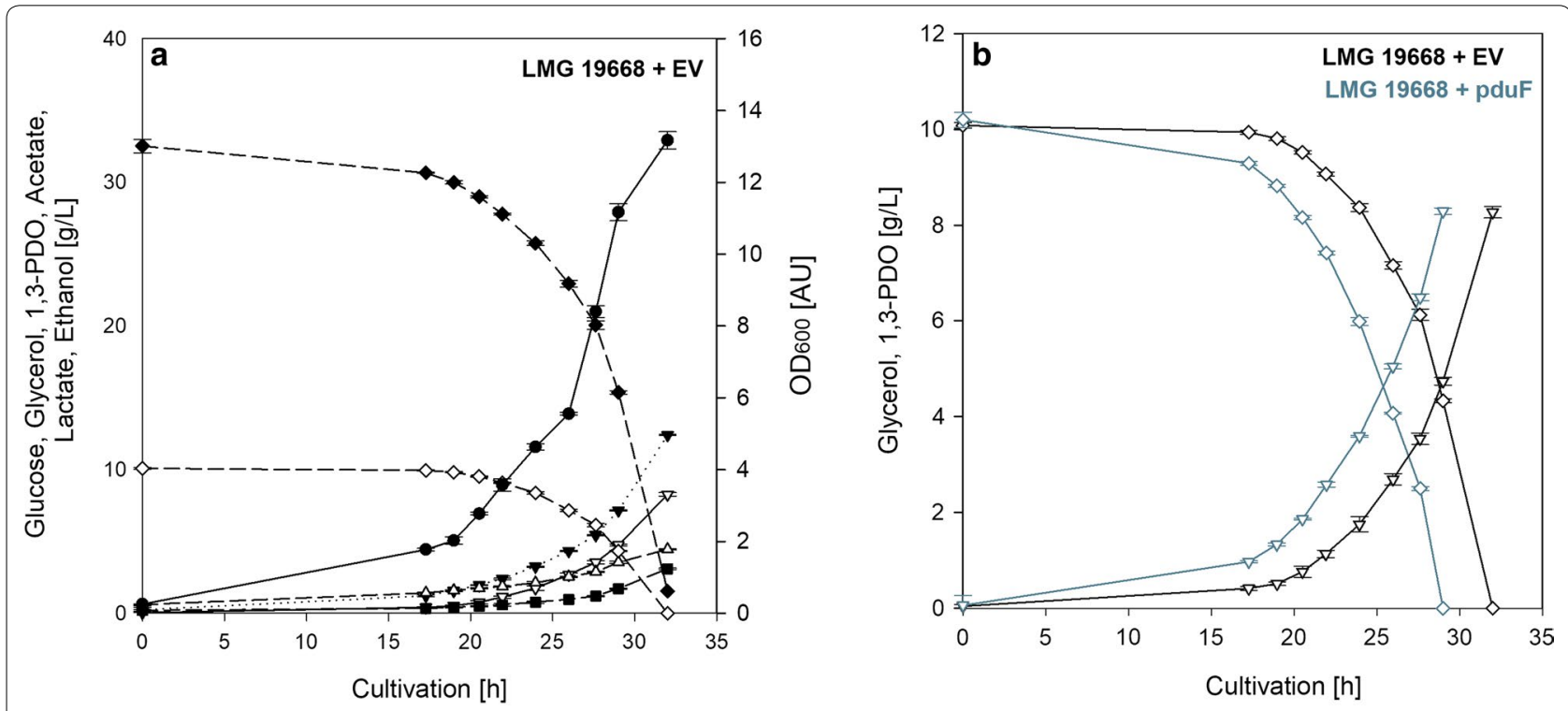

$\bullet$ OD600 $-\downarrow$ Glucose $-\diamond-$ Glycerol $\rightarrow-1,3-P D O \cdots-\cdots$ Lactate $-\Delta-$ Acetate --- Ethanol

Fig. 2 Batch cultivations of $L$. diolivorans. Illustration of batch cultivations on MRS-medium supplemented with glucose and glycerol of $L$. diolivorans LMG 19668 + EV (a) and comparison of this strain with L. diolivorans LMG 19668 + pduF strain in terms of glycerol uptake and 3-HPA formation capabilities (b)

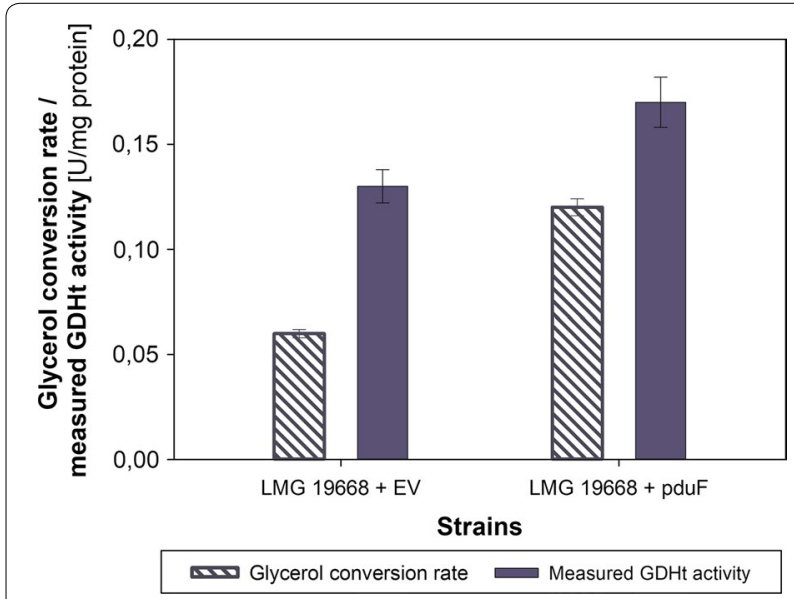

Fig. 3 Illustration of glycerol conversion capabilities in L. diolivorans. Comparison of the glycerol conversion rate and enzymatically measured GDHt activity during batch cultivations on MRS supplemented with glucose and glycerol of L. diolivorans LMG $19668+$ EV and L. diolivorans LMG $19668+$ pduF

diolivorans LMG 19668 + EV uses just 54\% of its actual glycerol dehydratase capabilities. This points to the fact that the glycerol dehydratase is not the limiting factor for glycerol conversion. In order to test, if the glycerol uptake is the limiting factor a genetic engineering approach was chosen aiming at the significant upregulation of glycerol uptake into the cell.
Genetic engineering aiming at the upregulation of glycerol uptake

In order to enhance the glycerol uptake of $L$. diolivorans, the endogenous glycerol uptake facilitating protein PduF was overexpressed from a recombinant plasmid. This gene is part of the glycerol converting pdu operon of $L$. diolivorans and shows a high sequence similarity with glycerol uptake facilitator proteins for members of the species Lactobacillus. Moreover, there is a sequence similarity to the experimentally characterized glycerol facilitator GlpF from E. coli, which is responsible for the passive transport of small hydrophilic species like glycerol across the inner membrane [43]. Genome analysis also revealed that beside the $p d u F$ gene there are no further annotations for members of the major intrinsic protein (MIP) family (glycerol uptake facilitators, aquaporins), indicating the importance of this gene. In a baker's yeast based complementation assay, we could confirm the capability of the $p d u F$ encoded protein to enhance glycerol uptake (data not shown).

In order to determine differences related to the uptake of glycerol between the strains $L$. diolivorans LMG $19668+$ EV and L. diolivorans LMG $19668+$ pduF, batch cultures on MRS medium supplemented with 3\% $(\mathrm{w} / \mathrm{v})$ glucose and $1 \%(\mathrm{w} / \mathrm{v})$ glycerol were performed and the actual GDHt activity was determined towards the end of the exponential growth phase. The overexpression of $p d u F$ leads to a significant increase of the average glycerol 
uptake rate by a factor of 1.3 , from initially $0.21 \mathrm{~g} /\left(\mathrm{g}_{\mathrm{CDM}}\right.$ h) to $0.27 \mathrm{~g} /\left(\mathrm{g}_{\mathrm{CDM}} \mathrm{h}\right)\left(q_{\mathrm{s}, \max }=0.35 \mathrm{~g} /\left(\mathrm{g}_{\mathrm{CDM}} \mathrm{h}\right)\right)$. This points to the fact that the glycerol uptake has been limiting before (see Fig. 2b). Surprisingly, the measured GDHt activity in the L. diolivorans LMG 19668 + pduF strain is also increased, reaching a value of $0.17 \mathrm{U} / \mathrm{mg}$ protein at the end of the exponential growth phase and leaving again a gap between the potential for glycerol conversion based on measured GDHt activity and the actual rate of glycerol conversion (Fig. 3).

These results prove that the overexpression of $p d u F$ in $L$. diolivorans has a positive effect on the glycerol uptake rates and they indicate that overexpression of $p d u F$ leads to significantly higher GDHt activity values.

\section{Increased induction of glycerol dehydratase activity in $L$. diolivorans}

Though GDHt featured significantly higher activity values in the strain overexpressing $p d u F$, the overall measured GDHt activity of $0.17 \mathrm{U} / \mathrm{mg}$ protein is still low for an efficient 3-HPA production process. To further increase the activity of glycerol dehydratase, glycerol is substituted with 1,2-PDO as inducing agent in the growth medium. This has been reported to achieve significantly higher dehydratase activity values for $L$. reuteri [44].

For the generation of active biomass, batch cultures on MRS medium supplemented with 3\% (w/v) glucose and $0.5 \%(\mathrm{w} / \mathrm{v}) 1,2-\mathrm{PDO}$ were performed. It could be demonstrated that the addition of 1,2-PDO or glycerol leads to a similar growth behavior, though the supplementation with 1,2-PDO yields a significantly higher measured GDHt activity $(0.85 \mathrm{U} / \mathrm{mg}$ protein or $1.11 \mathrm{U} / \mathrm{mg}$ protein for the strains L. diolivorans LMG $19668+$ EV or L. diolivorans LMG $19668+$ pduF, respectively). Also in this case, the $p d u F$ overexpressing strain has an enhanced activity compared to the empty vector control. Interestingly, the obtained activity is also significantly higher compared to the reported GDHt activity of $0.55 \mathrm{U} / \mathrm{mg}$ protein for $L$. reuteri induced by a comparable amount of 1,2-PDO (Table 1).

\section{Bioconversion of glycerol with resting cells of $L$. diolivorans} For the production of 3-HPA, a two-step cultivation process consisting of the generation of active biomass, followed by a quick bioconversion of glycerol, is the most promising approach. This two-step process design has been reported to achieve the best results with other microbial cell factories in terms of high GDHt activity, high productivities, and suppression of by-product formation [27]. Therefore, bioconversion experiments using active cells of either $L$. diolivorans LMG $19668+$ EV or $L$. diolivorans LMG $19668+$ pduF with 1,2-PDO as inducing agent were performed on $2 \%(\mathrm{w} / \mathrm{v})$ crude glycerol.
Table 1 Evaluation of GDHt activity in Lactobacillus diolivorans

\begin{tabular}{lll}
\hline & Glucose + Glycerol & Glucose + 1,2-PDO \\
\hline L. diolivorans & $56 \mathrm{mM} / 109 \mathrm{mM}$ & $56 \mathrm{mM} / 68 \mathrm{mM}$ \\
LMG19668 + EV & $0.13 \mathrm{U} / \mathrm{mg}$ protein & $0.85 \mathrm{U} / \mathrm{mg}$ protein \\
L. diolivorans & $56 \mathrm{mM} / 109 \mathrm{mM}$ & $56 \mathrm{mM} / 68 \mathrm{mM}$ \\
LMG19668 + pduF & $0.17 \mathrm{U} / \mathrm{mg}$ protein & $1.11 \mathrm{U} / \mathrm{mg} \mathrm{protein}$ \\
L. reuteri 20016 [44] & $15 \mathrm{mM} / 50 \mathrm{mM}$ & $15 \mathrm{mM} / 50 \mathrm{mM}$ \\
& $0.07 \mathrm{U} / \mathrm{mg}$ protein & $0.55 \mathrm{U} / \mathrm{mg}$ protein \\
\hline
\end{tabular}

Comparison of enzymatically measured GDHt activities derived from cultivations on glucose supplemented with either glycerol or 1,2-PDO including the strains $L$. diolivorans LMG 19668 + EV, L. diolivorans LMG 19668 + pduF, and L. reuteri

The bioconversion experiments showed that activated cells of $L$. diolivorans were excellent whole cell biocatalysts for the production of 3-HPA (Fig. 4). L. diolivorans LMG 19668 + pduF exhibited a significantly higher average glycerol uptake rate $\left(q_{\mathrm{S}}=8.7 \mathrm{~g} /\left(\mathrm{g}_{\mathrm{CDM}} \mathrm{h}\right), 0.5 \mathrm{~h}\right)$ as compared to the empty vector control $\left(q_{\mathrm{S}}=4.2 \mathrm{~g} /\right.$ $\left.\left(\mathrm{g}_{\mathrm{CDM}} \mathrm{h}\right), 1 \mathrm{~h}\right)$. Within the first $0.5 \mathrm{~h}$ hardly any formation of 1,3-PDO and 3-HP was observed. Interestingly, by-product formation significantly increased after around $0.5 \mathrm{~h}$ for both strains, indicating potential timedependent effects of increased 3-HPA levels in the fermentation broth. Possibly, rising energy requirements of the biocatalyst under stressful conditions lead to the slow dissipation of 3-HPA to 3-HP and 1,3-PDO. L. diolivorans LMG $19668+$ pduF accumulated a maximum of $17.8 \mathrm{~g} / \mathrm{L} \mathrm{3-HPA}$ with a molar yield of $99 \%$ and an average productivity of $q_{3-\mathrm{HPA}}=5 \mathrm{~g} /\left(\mathrm{g}_{\mathrm{CDM}} \mathrm{h}\right)$. In contrast to this, the LMG $19668+$ EV strain exhibited a significantly higher level of by-product formation yielding a maximum of $15.8 \mathrm{~g} / \mathrm{L} 3-\mathrm{HPA}$ with a molar yield of $90 \%$ within $1 \mathrm{~h}$. Additional File 3: Figure S3 illustrates the glycerol conversion rates during the 3-HPA production phase. The biocatalyst activity is gradually decreasing and leveling off around $0.5 \mathrm{U} / \mathrm{mg}$ protein upon complete consumption of glycerol. The apparent 3-HPA productivity has been compared with the measured GDHt activity after $10 \mathrm{~min}$ of the bioconversion reaction. As before, the in vitro measured GDHt activity is with $1.70 \mathrm{U} / \mathrm{mg}$ protein ( $L$. diolivorans $\mathrm{LMG}$ $19668+\mathrm{EV}$ ) and $2.23 \mathrm{U} / \mathrm{mg}$ protein (L. diolivorans LMG $19668+$ pduF) significantly higher than the obtained glycerol conversion rates.

\section{Improving the performance of glycerol bioconversion in $L$. diolivorans}

To produce industrially relevant levels of 3-HPA, overall titers need to be increased. Therefore, initial glycerol concentrations for the bioconversion process were raised from initially $2 \%(\mathrm{w} / \mathrm{v})$ to $5 \%(\mathrm{w} / \mathrm{v})$ crude glycerol. 

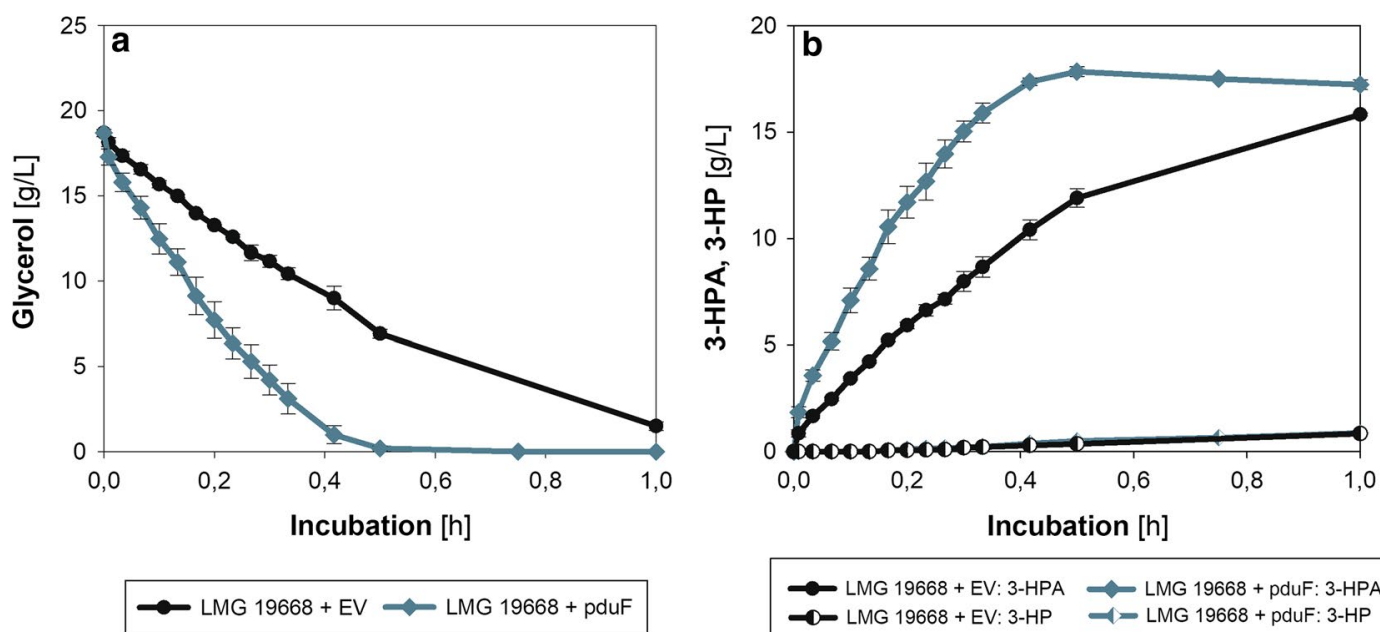

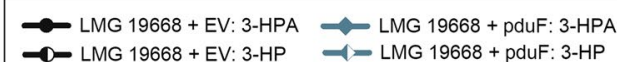

Fig. 4 Bioconversion of glycerol by L. diolivorans. Illustration of glycerol consumption (a) and 3-HPA as well as 3-HP formation (b) during bioconversion of L. diolivorans LMG 19668 + EV (black) and L. diolivorans LMG 19668 + pduF (blue) on 2\% glycerol. For a better illustration, levels of 1,3-PDO which are formed in equimolar amounts of 3-HP are not displayed in this figure. The active biomass for these bioconversion experiments was generated during batch cultivations on MRS-medium supplemented with 1,2-PDO

This increase in initial glycerol concentration leads to an increase in final titers up to $28 \mathrm{~g} / \mathrm{L} 3-\mathrm{HPA}$, however at the cost of productivity $q_{3-\mathrm{HPA}}=3.5 \mathrm{~g} / \mathrm{g}_{\mathrm{CDM}} \mathrm{h}$ and a low yield of $0.70 \mathrm{~mol}_{3-\mathrm{HPA}} / \mathrm{mol}_{\text {Glycerol }}$ due to incomplete utilization of glycerol and increased by-product formation of around 1.3 and $1.2 \mathrm{~g} / \mathrm{L}$ for $3-\mathrm{HP}$ and 1,3-PDO, respectively (Fig. 5).

To overcome low productivities and ensure a complete utilization of glycerol, the amount of activated biocatalyst was increased from initially $5 \mathrm{~g} / \mathrm{L} \mathrm{CDW}$ up to $15 \mathrm{~g} / \mathrm{L}$ CDW (Fig. 5). This increase in biocatalyst during bioconversions on $5 \%$ glycerol had a beneficiary effect on productivity, which reached $4.8 \mathrm{~g} / \mathrm{g}_{\mathrm{CDM}} \mathrm{h}-$ similar to the performance on $2 \%(\mathrm{w} / \mathrm{v})$ glycerol and with lower biocatalyst concentration. Furthermore, the overall titer could be improved to $36 \mathrm{~g} / \mathrm{L} 3-\mathrm{HPA}$, corresponding to a molar yield of $91 \%$. By-product formation using this approach was slightly increased up to 1.4 and $1.3 \mathrm{~g} / \mathrm{L}$ for $3-\mathrm{HP}$ and 1,3-PDO, respectively.

\section{Repeated batch bioconversions of $L$. diolivorans}

A drawback of the two-step production process is the necessity of large amounts of active biomass. Biomass production has a significant impact on overall process costs. It also has a significant impact on real product yields because the carbon source required for the generation of active biomass must be taken into account from an industrial point of view. One option to circumvent this problem is the recycling of biomass at the end of the bioconversion process.

Therefore, cells from the end of a 3-HPA production process on $2 \%(\mathrm{w} / \mathrm{v})$ glycerol were harvested, washed,

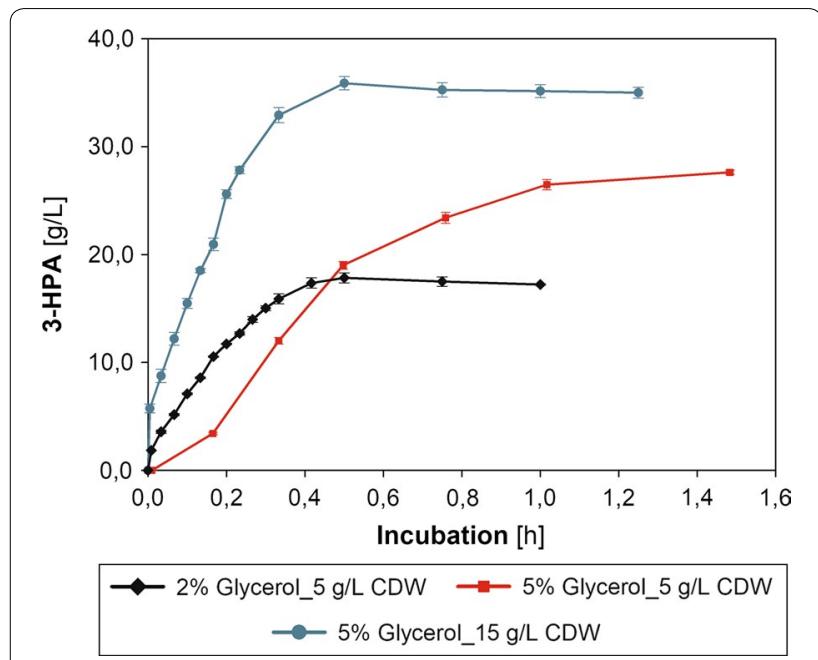

Fig. 5 Effect of variations in initial glycerol concentration and amount of biocatalyst on production performance. Illustration of 3-HPA formation for L. diolivorans LMG 19668 + pduF for bioconversion processes starting with $5 \mathrm{~g} / \mathrm{L} \mathrm{CDW}$ biocatalyst and $2 \%$ (black) or 5\% crude glycerol (red) as well as $15 \mathrm{~g} / \mathrm{L} \mathrm{CDW}$ biocatalyst and 5\% crude glycerol (blue). The active biomass for these bioconversion experiments was generated during batch cultivations on MRSmedium supplemented with 1,2-PDO

and incubated in a fresh bioconversion media. However, 3-HPA accumulation started only after a significant lag phase of $15 \mathrm{~min}$ (data not shown). Therefore, also dehydratase activities measured after $10 \mathrm{~min}$ of incubation were very low $(0.17 \mathrm{U} / \mathrm{mg}$ protein for $L$. diolivorans LMG $19668+\mathrm{EV}$ and $0.26 \mathrm{U} / \mathrm{mg}$ protein for L. diolivorans LMG 19668 + pduF, data not shown). Glycerol 
utilization stopped after $0.5 \mathrm{~h}$ reaching a final titer of only $9 \mathrm{~g} / \mathrm{L} 3-\mathrm{HPA}$ and a molar yield of $45 \%$ due to the incomplete utilization of glycerol. This indicates that the cells are severely damaged by the high 3-HPA concentrations to which they have been exposed during the first round of production. Hence, repeated batch bioconversion is not a suitable strategy for decreasing the amount of required active biomass without any protection of the biocatalyst.

\section{Comparison of the bioconversion of glycerol to 3-HPA by $L$.} diolivorans to other cell factories

To our knowledge, the best values for biotechnological production of 3-HPA have been obtained with $L$. reuteri. Results obtained from $L$. reuteri cells activated with glycerol show that this organism is capable of producing up to $17.4 \mathrm{~g} / \mathrm{L} 3$-HPA from $36.8 \mathrm{~g} / \mathrm{L}$ glycerol with a molar yield of $62 \%$ [45]. Decreasing the glycerol concentration to $20 \mathrm{~g} / \mathrm{L}$ leads to an improved molar yield of $85 \%$ on the expense of the final 3-HPA concentration $(12.6 \mathrm{~g} / \mathrm{L})$ [46, 47]. 1,2-PDO-activated cells of $L$. diolivorans-in comparison-accumulate $17.8 \mathrm{~g} / \mathrm{L} 3$-HPA from $2 \%$ crude glycerol with a molar yield of $99 \%$.

A major point of hindrance for microbial production of 3-HPA is its toxicity, which has a serious negative impact on cell viability and pathway enzyme activity $[35,48]$. One approach for overcoming these limitations is the protection of the biocatalyst by the application of scavengers like semicarbazide or carbohydrazide which are binding 3-HPA in form of hydrazone complexes and thereby allowing the accumulation of higher 3-HPA concentrations in the fermentation broth. Bioconversion using 1,2-PDO activated cells of $L$. reuteri in combination with semicarbazide as scavenger results in the production of $26 \mathrm{~g} / \mathrm{L} 3$-HPA from $5 \%$ glycerol with a productivity of $1.7 \mathrm{~g} /\left(\mathrm{g}_{\mathrm{CDM}} \mathrm{h}\right)$ [24]. L. diolivorans cells activated by 1,2-PDO reach similar titers however with a significantly higher productivity of $3.5 \mathrm{~g} /\left(\mathrm{g}_{\mathrm{CDM}} \mathrm{h}\right)$ in the absence of any scavengers-indicating superior biocatalyst properties under the tested conditions. Currently, L. reuteri features with the production of up to $150 \mathrm{~g} / \mathrm{L} 3-\mathrm{HPA}$ and a productivity of $10.7 \mathrm{~g} / \mathrm{L} \mathrm{h}$ the best 3-HPA production process [49]. However, the costs of scavengers and the increased costs for purification need to be taken into account.

Among other bacteria, Klebsiella pneumoniae is an alternative production host for 3-HPA. Its ability to use glycerol as a sole carbon source leads to a significant loss of substrate for biomass formation in case of growing cells. In a bioconversion process including scavengers, final titers of $46 \mathrm{~g} / \mathrm{L}$ of 3 -HPA with molar yields up to $80 \%$ are reported for this organism [50]. 3-HPA production within a fed-batch process featuring high scavenger concentrations and successive addition of active biomass was reported to achieve yields up to $97 \%$ (not taking the formation of biomass into account) thereby reaching the highest reported final titer of $54 \mathrm{~g} / \mathrm{L}$ 3-HPA [51]. However, $K$. pneumoniae is considered a human pathogen, a characteristic which limits its industrial applications.

Another promising candidate for 3-HPA production is Citrobacter freundii. The highest concentrations of 3-HPA are reported for the $C$. freundii mutant strain HPAO- 1 by obtaining a yield of $92 \%$ from $5 \%$ glycerol in the presence of semicarbazide hydrochloride [52].

\section{Conclusion}

This study demonstrates for the first time the potential of $L$. diolivorans as a valuable cell factory for the valorization of crude glycerol towards 3-HPA extending the C3 product range from 1,3-PDO and 3-HP towards platform chemicals like acrolein and acrylic acid. The combinatorial approach of process and metabolic engineering enabled to overcome bottlenecks associated with glycerol uptake and significantly upregulated the activity of glycerol dehydratase. Based on our results, we propose an integrated biodiesel biorefinery concept (Fig. 6) where crude glycerol is upgraded in a first step into 1,3-PDO [28-30]. It could be demonstrated in previous studies that $L$. diolivorans is a promising cell factory for the production of 1,3-PDO from crude glycerol achieving maximum titers of $92 \mathrm{~g} / \mathrm{L} 1,3-\mathrm{PDO}$ with a molar yield up to $94 \%$ [30]. In order to improve the economic viability of the overall biorefinery concept, the valorization of side streams (beside crude glycerol) into new product and value streams is of major importance. The biomass obtained from the production of 1,3-PDO (0.09 ton $\mathrm{CDM} /$ ton 1,3-PDO) can be employed within a next process step upgrading crude glycerol into $3-\mathrm{HPA}$, which is another product of interest. Considering a 3-HPA production process as described in this study, maximum titers of $36 \mathrm{~g} / \mathrm{L} 3-\mathrm{HPA}$ with a molar yield of $91 \%$ can be obtained using $L$. diolivorans as microbial cell factory. The biomass obtained for the production of 1 ton of 1,3PDO will allow the production of 0.21 tons of 3-HPA. A continuous supply of biomass originating from 1,3-PDO production eliminates the need for scavengers during 3-HPA production to protect the biomass. Moreover, the carbon-rich waste stream-mainly acetic acid-from the first process step can be used as input for biogas production. Acetic acid yields an energy output of $1300 \mathrm{kWh}$ as methane if fed into a classical biogas fermentation. This concept is depicted in Fig. 6.

1,3-PDO as well as 3-HPA represent both interesting platform chemicals-the former as precursor chemical for the production of polyesters like polytrimethylene terephthalate (PTT) [53] and the latter one for the production of acrolein [54]. Bioprocesses for the production 


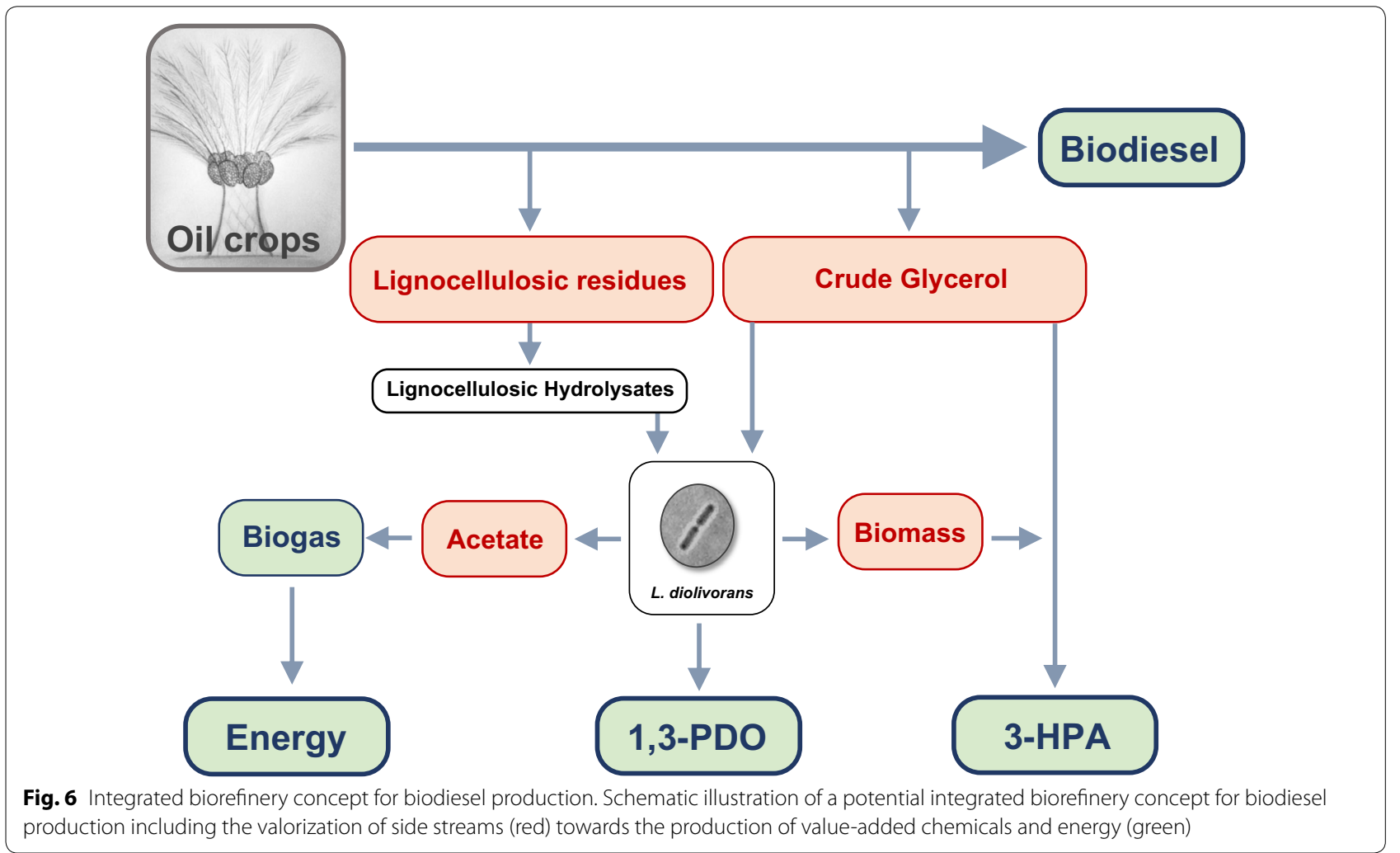

of both compounds from glycerol have been suggested in the literature. Among other lactic acid bacteria, L. reuteri has been reported to achieve 1,3-PDO productivities and yields comparable to $L$. diolivorans, though the maximum titers are with $65 \mathrm{~g} / \mathrm{L}$ 1,3-PDO significantly lower [55]. For 3-HPA production with $L$. reuteri, a titer of $150 \mathrm{~g} / \mathrm{L}$ has been reported-however, using scavengers to protect the cells [49]. The best 1,3-PDO process described to date is based on a recombinant $E$. coli strain within a fed-batch cultivation process with titers of $135 \mathrm{~g} / \mathrm{L} 1,3-\mathrm{PDO}$, a productivity of $3.5 \mathrm{~g} /(\mathrm{Lh})$, and a weight yield of $51 \%$ based on corn-derived glucose [56]. The productivity is excellent; however, glucose as carbon source appears undesirable in context with our proposed biodiesel biorefinery concept. The significance of our proposed concept is the beneficial effect which can be derived by combining the two L. diolivorans-based production processes for 1,3-PDO and 3-HPA and integrating them into a biodiesel refinery. This results in a maximum valorization of the crude glycerol side stream into more profitable biochemicals. Furthermore, it significantly enhances the economics of 3-HPA production by eliminating the need for additional seed reactors containing cost-intensive MRS-medium for biomass generation or the application of scavengers for biomass recycling. In addition to this, the setup is also beneficiary for the step of 1,3-PDO production as the both major side streams (acetic acid, biomass) are continuously used in a next step. To conclude, this approach demonstrates an opportunity for creating an integrated oil plant-based biorefinery, producing biodiesel, 1,3PDO, 3-HPA, and a significant amount of energy in form of biogas.

\section{Additional files}

Additional file 1: Figure S1. L. diolivorans LMG $19668+$ pduF. Schematic illustration of the BB3_AB_pGAP_pduF_TT CAT plasmid of $L$. diolivorans LMG 19668 + pduF. The BB3 linker includes an erythromycin resistance cassette from pSIP409 (ErmB) and kanamycin resistance cassette from pSTBLUE (Kan), the origin of replication from L. diolivorans (repA) and the origin of replication for E. coli from pUC19 (pUC_origin). The expression cassette includes the promoter of the glyceraldehyde 3-phosphate dehydrogenase (pGAP) from L. diolivorans, the terminator of the chloramphenicol resistance cassette (TT_CAT) from pC194 as well as pduF from L. diolivorans as the gene of interest. Table S1. Overview of strains and plasmids. Table $\mathbf{S 2}$. Primers used for PCR reactions.

Additional file 2: Figure S2. HPLC chromatograms. Illustration of a section of the peak pattern of the $5 \mathrm{~g} / \mathrm{L}$ standard solutions of 3-HPA, 1,3-PDO and $3-\mathrm{HP}(\mathrm{A}, \mathrm{C})$ as well as the combination of these standards with the peak pattern of samples derived from bioconversion experiments $(B, D)$ by using the RID detector (A, B) or the UV-VIS detector at $210 \mathrm{~nm}(C, D)$.

Additional file 3: Figure S3. Glycerol conversion rates during bioconversion. Illustration of the glycerol conversion rates of the strains $L$. diolivorans LMG 19668 + EV (black) and L. diolivorans LMG 19668 + pduF (blue) during bioconversion on $2 \%$ glycerol. 


\section{Abbreviations}

1,3-PDO: 1,3-propanediol; 3-HP: 3-hydroxypropionic acid; 3-HPA: 3-hydroxypropionaldehyde; GDHt: glycerol dehydratase; GHG: greenhouse gas emissions; MIP: major intrinsic proteins; PTT: polytrimethylene terephthalate; $y A D H$ : yeast alcohol dehydrogenase.

\section{Authors' contributions}

The study was designed by HM, KAL, and MS. KAL performed the experiments and analyzed the results together with MS and HM. The manuscript was drafted by KAL with contributions from all authors. All authors read and approved the final manuscript.

\section{Author details}

${ }^{1}$ CD-Laboratory for Biotechnology of Glycerol, University of Natural Resources and Life Sciences, Vienna, Muthgasse 18, 1190 Vienna, Austria. ${ }^{2}$ Department of Biotechnology, University of Natural Resources and Life Sciences, Vienna, Muthgasse 18, 1190 Vienna, Austria. ${ }^{3}$ Austrian Centre of Industrial Biotechnology (ACIB GmbH), Muthgasse 11, 1190 Vienna, Austria.

\section{Acknowledgements}

We thank Stefanie Wiesauer for her help during the fermentation experiments and enzymatic assays as well as the Christian Doppler Research Association and Vogelbusch GmbH, Vienna, Austria for funding this project.

\section{Competing interests}

The authors declare that they have no competing interests.

\section{Availability of data and materials}

The datasets used and/or analyzed during the current study are available from the corresponding author on reasonable requests.

\section{Consent for publication}

Not applicable.

\section{Ethics approval and consent to participate}

Not applicable.

\section{Funding}

This work was financially supported by the Christian Doppler Research Association and Vogelbusch GmbH, Vienna, Austria.

\section{Publisher's Note}

Springer Nature remains neutral with regard to jurisdictional claims in published maps and institutional affiliations.

Received: 3 October 2017 Accepted: 26 November 2017 Published online: 07 December 2017

\section{References}

1. IPCC. Climate change 2014: mitigation of climate change. Working group III contribution to the Fifth assessment report of the intergovernmental panel on climate change. In: Edenhofer O, R. Pichs-Madruga, Y. Sokona, E. Farahani, S. Kadner, K., Seyboth AA, I. Baum, S. Brunner, P. Eickemeier, B. Kriemann, J. Savolainen, S. Schlömer, C. von Stechow, T. Zwickel and J.C., Minx editors. Cambridge: Cambridge University Press; 2014.

2. Akimoto K, Sano F, Tehrani BS. The analyses on the economic costs for achieving the nationally determined contributions and the expected global emission pathways. Evolut Inst Econ Rev. 2017;14:193-206.

3. UNFCCC. Adoption of the Paris Agreement. Draft Decision: CP.21, FCCC/ CP/2015/L.9/Rev.1. 2015.

4. IEA: World Energy Outlook 2016. International Paris: Energy Agency; 2016.

5. OECD-FAO. OECD-FAO Agricultural Outlook 2016-2025. Paris: OECD Publishing; 2016.

6. Johnson DT, Taconi KA. The glycerin glut: options for the value-added conversion of crude glycerol resulting from biodiesel production. Environ Prog. 2007;26:338-48.
7. Vivek N, Sindhu R, Madhavan A, Anju AJ, Castro E, Faraco V, Pandey A, Binod P. Recent advances in the production of value added chemicals and lipids utilizing biodiesel industry generated crude glycerol as a substrate - metabolic aspects, challenges and possibilities: an overview. Bioresour Technol. 2017;239:507-17.

8. Chen Z, Liu D. Toward glycerol biorefinery: metabolic engineering for the production of biofuels and chemicals from glycerol. Biotechnol Biofuels. 2016;9:205

9. Haas MJ, McAloon AJ, Yee WC, Foglia TA. A process model to estimate biodiesel production costs. Bioresour Technol. 2006;97:671-8.

10. Samul D, Leja K, Grajek W. Impurities of crude glycerol and their effect on metabolite production. Ann Microbiol. 2014;64:891-8.

11. Thompson JC, He BB. Characterization of crude glycerol from biodiesel production from multiple feedstocks. Appl Eng Agric. 2006;22:261-5.

12. Oleoline. Glycerine Market Report. 2017. http://oleo-oleoline.com. Accessed 19 Sept 2017.

13. Bozell JJ. Feedstocks for the future-biorefinery production of chemicals from renewable carbon. Clean. 2008;36:641-7.

14. Dubois JL. Refinery of the future: feedstock, processes, products. In: Aresta M, Dibenedetto A, Dumeignil F, editors. Biorefinery: from biomass to chemicals and fuels. Walter de Gruyter; 2012. p. 19-48.

15. AtlanticResearchChemicals: 3-hydroxypropanal. Atlantic Research Chemicals Ltd. 2017. http://atlantic-chemicals.com. Accessed 19 Sept 2017.

16. Schaefer $L$, Auchtung TA, Hermans KE, Whitehead D, Borhan B, Britton RA. The antimicrobial compound reuterin (3-hydroxypropionaldehyde) induces oxidative stress via interaction with thiol groups. Microbiology. 2010;156:1589-99.

17. Werpy T, Petersen G, Aden A, Bozell J, Holladay J, White J, Manheim A, Eliot D, Lasure $L$, Jones $\mathrm{S}$. Top value added chemicals from biomass. Volume 1-results of screening for potential candidates from sugars and synthesis gas. Department of Energy Washington; 2004.

18. Vollenweider S, Lacroix C. 3-Hydroxypropionaldehyde: applications and perspectives of biotechnological production. Appl Microbiol Biotechnol. 2004;64:16-27.

19. Almeida JRM, Fávaro LCL, Quirino BF. Biodiesel biorefinery: opportunities and challenges for microbial production of fuels and chemicals from glycerol waste. Biotechnol Biofuels. 2012;5:48.

20. Clomburg JM, Gonzalez R. Anaerobic fermentation of glycerol: a platform for renewable fuels and chemicals. Trends Biotechnol. 2013;31:20-8.

21. Clomburg JM, Gonzalez R. Biofuel production in Escherichia coli: the role of metabolic engineering and synthetic biology. Appl Microbiol Biotechnol. 2010;86:419-34.

22. El-Ziney MG, Arneborg N, Uyttendaele M, Debevere J, Jakobsen M. Characterization of growth and metabolite production of Lactobacillus reuteri during glucose/glycerol cofermentation in batch and continuous cultures. Biotechnol Lett. 1998;20:913-6.

23. Barbirato F, Grivet JP, Soucaille P, Bories A. 3-Hydroxypropionaldehyde, an inhibitory metabolite of glycerol fermentation to 1,3-propanediol by enterobacterial species. Appl Environ Microbiol. 1996;62:1448-51.

24. Dishisha T, Pereyra LP, Pyo S-H, Britton RA, Hatti-Kaul R. Flux analysis of the Lactobacillus reuteri propanediol-utilization pathway for production of 3-hydroxypropionaldehyde, 3-hydroxypropionic acid and 1,3-propanediol from glycerol. Microb Cell Fact. 2014;13:1.

25. Sauer M, Russmayer H, Grabherr R, Peterbauer CK, Marx H. The efficient clade: lactic acid bacteria for industrial chemical production. Trends Biotechnol. 2017;35:756-69.

26. Kumar V, Sankaranarayanan M, Durgapal M, Zhou S, Ko Y, Ashok S, Sarkar $\mathrm{R}$, Park S. Simultaneous production of 3-hydroxypropionic acid and 1,3-propanediol from glycerol using resting cells of the lactate dehydrogenase-deficient recombinant Klebsiella pneumoniae overexpressing an aldehyde dehydrogenase. Bioresour Technol. 2013;135:555-63.

27. Talarico T, Casas I, Chung TC, Dobrogosz W. Production and isolation of reuterin, a growth inhibitor produced by Lactobacillus reuteri. Antimicrob Agents Chemother. 1988;32:1854-8.

28. Pflügl S, Marx H, Mattanovich D, Sauer M. 1,3-Propanediol production from glycerol with Lactobacillus diolivorans. Bioresour Technol. 2012;119:133-40

29. Pflügl S, Marx H, Mattanovich D, Sauer M. Heading for an economic industrial upgrading of crude glycerol from biodiesel production to 1,3-propanediol by Lactobacillus diolivorans. Bioresour Technol. 2014;152:499-504. 
30. Lindlbauer KA, Marx H, Sauer M. Effect of carbon pulsing on the redox household of Lactobacillus diolivorans in order to enhance 1,3-propanediol production. N Biotechnol. 2017;34:32-9.

31. Sarkari P, Marx H, Blumhoff ML, Mattanovich D, Sauer M, Steiger MG. An efficient tool for metabolic pathway construction and gene integration for Aspergillus niger. Bioresour Technol. 2017;245:1327-33.

32. Pflügl S, Marx H, Mattanovich D, Sauer M. Genetic engineering of Lactobacillus diolivorans. FEMS Microbiol Lett. 2013;344:152-8.

33. De Man JC, Rogosa M, Sharpe ME. A medium for the cultivation of Lactobacilli. J Appl Bacteriol. 1960;23:130-5.

34. Burgé G, Flourat A, Pollet B, Spinnler H-E, Allais F. 3-Hydroxypropionaldehyde (3-HPA) quantification by HPLC using a synthetic acrolein-free 3-hydroxypropionaldehyde system as analytical standard. RSC Adv. 2015;5:92619-27.

35. Sankaranarayanan M, Seol E, Kim Y, Chauhan AS, Park S. Measurement of crude-cell-extract glycerol dehydratase activity in recombinant Escherichia coli using coupled-enzyme reactions. J Ind Microbiol Biotechnol. 2017:44:477-88

36. Bradford MM. A rapid and sensitive method for the quantitation of microgram quantities of protein utilizing the principle of protein-dye binding. Anal Biochem. 1976;72:248-54.

37. Bauer R, du Toit M, Kossmann J. Influence of environmental parameters on production of the acrolein precursor 3-hydroxypropionaldehyde by Lactobacillus reuteri DSMZ 20016 and its accumulation by wine lactobacilli. Int J Food Microbiol. 2010;137:28-31.

38. Altschul SF, Madden TL, Schäffer AA, Zhang J, Zhang Z, Miller W, Lipman DJ. Gapped BLAST and PSI-BLAST: a new generation of protein database search programs. Nucleic Acids Res. 1997;25:3389-402.

39. Altschul SF, Wootton JC, Gertz EM, Agarwala R, Morgulis A, Schäffer AA, Yu YK. Protein database searches using compositionally adjusted substitution matrices. FEBS J. 2005;272:5101-9.

40. Wei X, Meng X, Chen Y, Wei Y, Du L, Huang R. Cloning, expression, and characterization of coenzyme-B12-dependent diol dehydratase from Lactobacillus diolivorans. Biotechnol Lett. 2014;36:159-65.

41. Neidhardt FC, Curtiss R. Escherichia Coli and Salmonella: cellular and molecular biology. Washington: ASM Press; 1996.

42. Shokri A, Larsson G. Characterisation of the Escherichia coli membrane structure and function during fedbatch cultivation. Microb Cell Fact. 2004;3:9-10.

43. Maurel C, Reizer J, Schroeder JI, Chrispeels MJ, Saier M. Functional characterization of the Escherichia coli glycerol facilitator, GlpF, in Xenopus oocytes. J Biol Chem. 1994;269:11869-72.
44. Sriramulu DD, Liang M, Hernandez-Romero D, Raux-Deery E, Lünsdorf H, Parsons JB, Warren MJ, Prentice MB. Lactobacillus reuteri DSM 20016 produces cobalamin-dependent diol dehydratase in metabolosomes and metabolizes 1,2-propanediol by disproportionation. J Bacteriol. 2008;190:4559-67.

45. Doleyres Y, Beck P, Vollenweider S, Lacroix C. Production of 3-hydroxypropionaldehyde using a two-step process with Lactobacillus reuteri. Appl Microbiol Biotechnol. 2005;68:467-74.

46. Vollenweider S, Grassi G, König I, Puhan Z. Purification and structural characterization of 3-hydroxypropionaldehyde and its derivatives. J Agric Food Chem. 2003;51:3287-93.

47. Lüthi-Peng Q, Schärer S, Puhan Z. Production and stability of 3-hydroxypropionaldehyde in Lactobacillus reuteri. Appl Microbiol Biotechnol. 2002;60:73-80

48. Lim HG, Noh MH, Jeong JH, Park S, Jung GY. Optimum rebalancing of the 3-hydroxypropionic acid production pathway from glycerol in Escherichia coli. ACS Synth Biol. 2016;5:1247-55.

49. Hendrik Krauter TW, Vorlop KD. Production of high amounts of 3-hydroxypropionaldehyde from glycerol by Lactobacillus reuteri with strongly increased biocatalyst lifetime and productivity. N Biotechnol. 2011;29:211-7.

50. Vancauwenberge JE, Slininger PJ, Bothast RJ. Bacterial conversion of glycerol to beta-hydroxypropionaldehyde. Appl Environ Microbiol. 1990;56:329-32.

51. Ulmer C, Zeng A. Microbial production of 3-hydroxypropionaldehyde from glycerol bioconversion. Chem Biochem Eng Q. 2007;21:321-6.

52. West TP, Peterson JL. Elevated 3-hydroxypropionaldehyde production from glycerol using a Citrobacter freundii mutant. Biotechnol Lett. 2014;36:147-52.

53. MarketsAndMarkets. 1,3-Propanediol (PDO) market by applications (PTT, Polyurethane, Cosmetic, Personal Care \& Home Cleaning \& Others) \& geography_ global market trends \& forecasts to 2021 2015. http:// www.marketsandmarkets.com/Market-Reports/1-3-propanediol-pdomarket-760.html. Accessed 9 Nov 2017.

54. Behr A, Eilting J, Irawadi K, Leschinski J, Lindner F. Improved utilisation of renewable resources: new important derivatives of glycerol. Green Chem. 2008; 10:13-30

55. Jolly J, Hitzmann B, Ramalingam S, Ramachandran KB. Biosynthesis of 1,3-propanediol from glycerol with Lactobacillus reuteri: effect of operating variables. J Biosci Bioeng. 2014;118:188-94.

56. Nakamura CE, Whited GM. Metabolic engineering for the microbial production of 1,3-propanediol. Curr Opin Biotechnol. 2003;14:454-9.

\section{Submit your next manuscript to BioMed Central and we will help you at every step:}

- We accept pre-submission inquiries

- Our selector tool helps you to find the most relevant journal

- We provide round the clock customer support

- Convenient online submission

- Thorough peer review

- Inclusion in PubMed and all major indexing services

- Maximum visibility for your research

Submit your manuscript at www.biomedcentral.com/submit
BioMed Central 